See discussions, stats, and author profiles for this publication at: https://www.researchgate.net/publication/319101560

\title{
Espacios olvidados, lugares diferenciados: Transformación social del espacio urbano en Bogotá (1850-1880)
}

Article · July 2014

CITATIONS

8

1 author:

Fabián Andrés Llano

Universitaria uniagustiniana

71 PUBLICATIONS 65 CITATIONS

SEE PROFILE

Some of the authors of this publication are also working on these related projects:

READS

191

\section{Project Enseñanza de la Gestión Urbana View project}

RELATOS SOBRE LA ENSEÑANZA Y COMUNIDADES NARRATIVAS. LA INVESTIGACIÓN (AUTO) BIOGRÁFICO - NARRATIVA COMO EJERCICIO EPISTÉMICO - POLÍTICO PARA LA RECUPERACIÓN DE LOS HÁBITATS SEMIÓTICOS EN LA EDUCACIÓN UNIVERSITARIA. View project 


\title{
Espacios olvidados, lugares diferenciados: Transformación social del espacio urbano en Bogotá (1850-1880)
}

\author{
Forgotten Spaces, distinct places: \\ Social transformation of urban space in Bogotá \\ (1850-1880)
}

Fabián Andrés Llano*

\section{Resumen}

El propósito de este artículo se vincula a las formas de recuperación de unos espacios sociales y urbanos caídos en el olvido que se evidencian en la transformación social del espacio urbano en Bogotá entre 1850 y 1880 . El texto vincula en primer lugar las discusiones en torno a la comprensión de la ciudad como una elaboración en el espacio, para pasar a describir, el crecimiento de la ciudad integrando sus estructuraciones históricas, sociales y culturales.

\section{Palabras clave}

Patrimonio urbano, preservación del hábitat, ciudad, ciudadanía, espacio social.

\section{Abstract}

The purpose of this article is linked to some forms of recovery of social and urban spaces fallen into oblivion that are evident in the social transformation of urban space in Bogotá between 1850 and 1880.The following paper presents the preliminary results of the research entitled practices and social uses of water in Bogotá (1850-1888). The text links in first discussions about the understanding of the city as a drawing in space, moving to describe, the growth of the city, integrating its historical, social and cultural structuring.

\section{Keywords}

Urban heritage, habitat preservation, city, citizenship, social space. 
"Ya no vive nadie en ella a la orilla del camino silenciosa esta la casa se diría que sus puertas se cerraron para siempre se cerraron para siempre sus ventanas".

Fragmento canción Las Acacias.

Pocos colombianos saben en realidad que la canción "Las acacias", inmortalizada por el dúo Silva y Villalba y coreada por multitud de colombianos en diferentes tiendas, bares y sobre todo al interior de diversidad de viviendas familiares, es en realidad un poema del español Vicente Medina Tomás, cuyos arreglos musicales han sido atribuidos al antioqueño Jorge Molina Cano. En el poema-canción se respira un espíritu de muerte y de recuerdo de aquellos que abandonaron un día la ciudad y tal como se pronuncia en el diario vivir, se exhala la ausencia de las personas que "pasaron a mejor vida". El recuerdo de los difuntos permanece en los lugares ocupados, en estas particularidades que brinda el habitar una casa, en las sensaciones de experiencias enmarcadas en la cotidianidad del barrio y por supuesto en las profundidades de la memoria de la ciudad.

La imagen de la casa en la canción se resiste a desvanecer a pesar de estar clausurada por el efecto del abandono y por la fuerza que ejerce el vacío de aquellos que partieron. Esta resistencia a disiparse, se manifiesta en los vestigios de un lugar habitado que ha caído en el aislamiento paulatino y en el abandono urbano. Es así como se logra partir desde unas imágenes que procura el fragmento de poemacanción, a propósito del habitar un lugar, hacia la reflexión sobre la memoria urbana. En efecto, acudir a una analogía en torno a lo que le acontece a la ciudad alrededor del abandono de los bogotanos por su espacio habitable, remite además, a la desaprobación estética de la casa vieja y al desvanecimiento de la memoria urbana de la ciudad.

Aunque existen intentos por la conservación de algunos inmuebles declarados patrimonio urbano en la ciudad y algunas iniciativas por mantener esta memoria urbana por medio de la fotografía ${ }^{1}$, las construcciones antiguas, la referencia a un pasado urbano y la demolición de viejos lugares de reconocimiento social y cultural para la ciudad, toman la forma de la casa narrada en el poema - canción las acacias. De esta manera, una apuesta por la visibilización de un pasado urbano y un intento por la recuperación de la memoria, permite entender como se ha transformado el espacio urbano, desde los tiempos en que Bogotá era considerada un caserío.

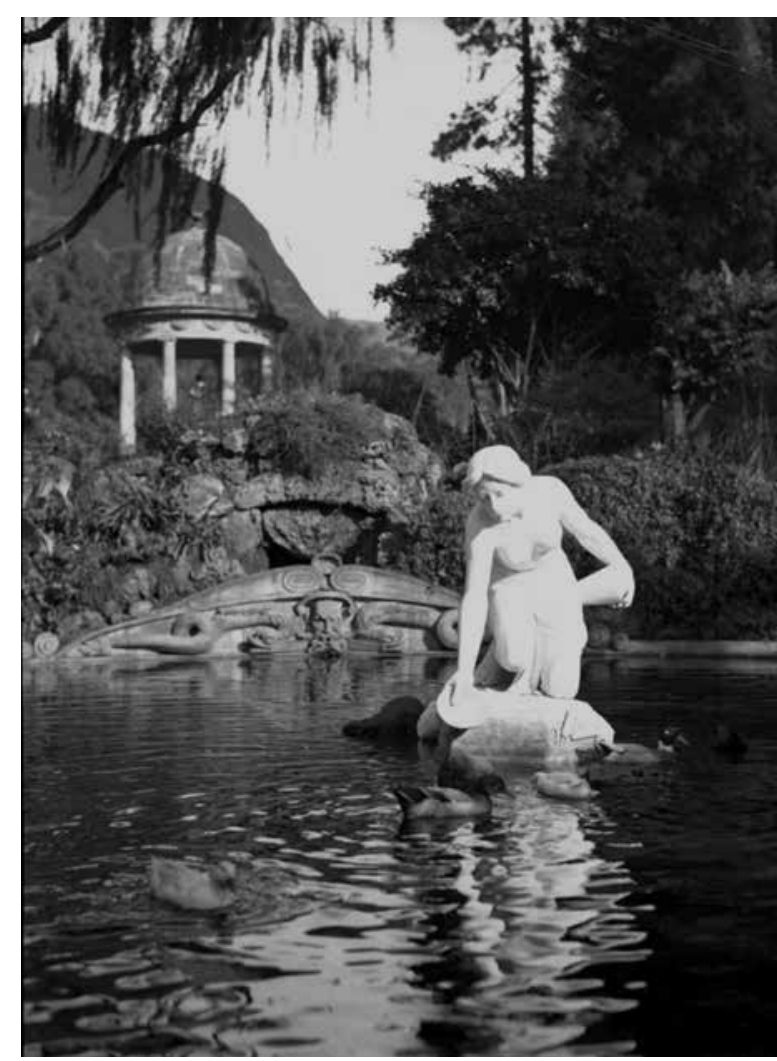

1 La biblioteca Luis Ángel Arango conserva una hermosa colección de imágenes del comerciante Gumersindo Cuéllar que cuenta con más de 2.000 fotografías desde 1928. El Banco de la República adquirió 2.190 fotografías de Gumersindo Cuéllar que conservaba su familia y que constituyen hoy su acervo fotográfico. En su mayoría, se trata de negativos en acetato en blanco y negro, de $9 \times 12 \mathrm{~cm}$. Como muchas colecciones en Colombia, las fotografías están sin clasificar ni datar, pero recubren un periodo aproximado de las tres decenios que van desde 1925 hasta 1955 . tomado de http://www.banrepcultural. org/blaavirtual/gumercindo-cuellar 
Entender desde una perspectiva de historia sociocultural la dinámica sobre el desarrollo urbano, requiere introducir en la discusión elementos que transversan las configuraciones de la ciudad como son las estructuraciones económicas, sociales y culturales de un espacio social y urbano fracturado $^{2}$. En este sentido, el propósito de este artículo se ocupa de las formas de recuperación de unos espacios caídos en el olvido, lugares diferenciados cargados de miserias y de exclusión social y espacial, que no han transitado por la memoria legitima de laciudad, si se tiene en cuenta que alrededor de la construcción del patrimonio urbano se desatan unas tensiones producto de unas fuerzas sociales en constante lucha por la imposición de unos sentidos legítimos. De este modo, al observar el crecimiento de la ciudad, desde una época en que era considerada un caserío, es posible aproximarse a comprender una de las mayores limitaciones del patrimonio urbano en Colombia: el desconocimiento de sus estructuraciones históricas, sociales y culturales.

En efecto, este desconocimiento no permite una construcción de un mundo público incluyente, donde todos los sectores participen de forma activa en la construcción de su espacio urbano. La ciudad en tanto, se encuentra inmiscuida en las más diversas relaciones de poder y de legitimación de los grupos sociales que la producen. Este fenómeno sociocultural complejo que requiere ser abordado desde una postura constructivista, que reivindique el contexto para superar la dicotomía en las definiciones del patrimonio urbano hoy reducido a categorizaciones folkloristas como patrimonio tangible (material) reduce sus posibilidades de relación con dinámicas sociales y culturales. Habría que advertir que las recomendaciones de la Unesco del 2011 en la definición del paisaje urbano aunque logra reconocer a los centros históricos como resultado de un proceso

2 Cfr. Llano, F. y Chavarro, C. (2010). El héroe, el lujo y la precariedad patrimonio histórico en Bogotá (1880-1950). Bogotá: Universidad La Gran Colombia. de estratificación donde convergen valores y atributos culturales, no inmiscuye las relaciones de fuerza que la atraviesan en la misma producción del paisaje urbano.

En suma, detrás de la construcción de ciudad se esconden diferentes agenciamientos que la hacen posible, aquí juegan un papel importante las diferentes instancias que participan en el embellecimiento de la ciudad junto con los diferentes agentes que movilizando sus intereses logran proyectar una imagen legitima de ciudad; a partir de la movilización de la producción como espacio urbano, se evidencia además las posiciones interesadas en proyectarla públicamente.

Finalmente, es importante advertir que estas dinámicas esconden una multiplicidad de relaciones que permiten que unos repertorios simbólicos y estéticos, puedan ser erigidos en patrimonios vivos, pero el verdadero peligro que se presenta es el desconocimiento de una memoria proscrita, de un pasado que no ha transitado por la historia oficial y han quedado sin posibilidad de explicación histórica o de reconocimiento en la ciudad conminándola a representarse como una "memoria canalla" ${ }^{3}$. Así, este desconocimiento de la historia que está detrás de la construcción espacial y social de la ciudad, no permite la inclusión de un pasado cargado de diferenciaciones sociales y culturales, donde las clases medias y bajas, generalmente han sido constantemente excluidas en la formación histórica de la ciudadanía.

3 Memoria canalla es uno de los proyectos ganadores del concurso "Ciudad y Patrimonio 2008" del Instituto Distrital de Patrimonio Cultural. Memoria Canalla recopiló durante 3 meses, en una exposición pública, parte de la historia desterrada y perseguida de los muros de Bogotá, parte de esa memoria que durante décadas ha estado presente de manera contundente y determinante en los recorridos de muchas y muchos bogotanos, pero que por su condición ilegal y ef ímera no ha sido tenida en cuenta cabalmente en espacios de estudio y exposición, haciendo justicia a su real importancia y valor.] tomado de http://colombia-wikiciudadana.blogspot. com/2009/10/memoria-canalla-graffiti-en-bogota.html 


\section{Aspectos teóricos}

\section{De las conceptualizaciones \\ fenomenológicas a las apuestas materiales de la ciudad}

La ciudad como una elaboración en el espacio, posee la cualidad de generar múltiples valoraciones dentro de diversos grupos sociales; capacidad que se ve reforzada si se tiene en cuenta el papel que desempeñan diferentes instancias, como la política, comunicación y las relaciones de fuerza que se presentan en su relación con la arquitectura. En efecto, esta experiencia del habitar los espacios urbanos transita en primer lugar, por unas visiones fenomenológicas donde se postula la experiencia como elemento indispensable del habitar, pasando por unas dimensiones simbólicas que entienden la ciudad como un texto y finalmente por aquellas posiciones que logran coincidir en las apuestas materiales sostenidas en los efectos económicos que logran redireccionar a la ciudad, alrededor de una visión un tanto proclive a entender las dinámicas de la ciudad en relación a la configuración de un espacio social y urbano mediado por múltiples relaciones de fuerza.

Desde una dimensión fenomenológica una comprensión de la vivienda supone la experiencia y el sentido del habitar un entorno. Sobre el tema de la vivienda habría que realizar el siguiente interrogante ¿Qué lleva al hombre a construir su casa? $\mathrm{Y}$ ¿qué sentido cobra el habitar con el entorno? La resolución de tales interrogantes no puede desligarse de la condición humana bajo dos criterios fundamentales: la necesidad de comodidad y el deseo de protección. (En efecto, bajo la protección y la comodidad se soporta la acción de construir un lugar, una casa, un espacio, cuya función es el habitar donde solo se puede ser "ahí", esto es, sentirse en casa.

Sin embargo, la relación del habitar necesita unas condiciones de posibilidad o, como cuestiona Yory (1998), ¿De qué sirve un techo sin trabajo, sin salud ni educación y sin autoestima? Las condiciones materiales que posibilitan el albergue se liga a un orden ético y estético que permite pensar la ciudad como un espacio susceptible de ser leído, en realidad se postula metafóricamente como un libreto donde se ponen de manifiesto los significados que se producen en la relación hombre-entorno.

Desde esta perspectiva, la transformación de la ciudad moderna a través de la historia ha presentado algunas modificaciones importantes, pasando de las comunas (intereses claros integrados a un imaginario) a la ciudad como proyecto donde se busca la forma más apropiada de habitar. Ahora bien, esta adecuación que hoy se aleja del modelo clásico como posibilidad, es también simulacro que se dispone a ser leído como un texto por medio de los gestos y de las nuevas realidades que se construyen en la ciudad (Llano, 2013, citando a Yory, 1998).

Estas dinámicas del habitar, susceptibles de ser rastreadas como libretos en la ciudad, suponen la preservación de unas prácticas no oficiales en la urbe y la consideración de pobladores poco reconocidos. Esta simbología urbana procede bajo los efectos pedagógicos de modernizar lo antiguo, es decir, preservar y civilizar por medio de la presentación de unos objetos antiguos (casas, parques, edificaciones, monumentos, etc.) resignificados bajo unos criterios particulares (modernizantes) sin tener en cuenta, el significado de los verdaderos monumentos vivos que permanecen en el espacio urbano por mucho tiempo, pero que olvidados, son desplazados del hábitat.

En este sentido, se hace indispensable discurrir acerca de la importancia de la preservación de los objetos patrimoniales dentro del fenómeno de transformación urbana. Desde lo que De Certau (2010), llama la política de la restauración, donde se evidencia un desplazamiento del patrimonio vivido, de las experiencias pasadas encarnadas en pobladores urbanos, que por los efectos de la revalorización del suelo, son desplazados de sus territorios de origen. Esta política de la restauración afecta al hábitat urbano, desarraigando a los 
oriundos habitantes del lugar, que trasladados de sus propiedades se desarticulan de la experiencia histórica del lugar y dejan unos espacios carentes de efectos históricos experienciales, ahora convertidos en lugares atractivos para la vivienda de residentes acomodados financieramente.

El desarraigo de estos habitantes pasa por una desapropiación de los lugares habitados, por la expropiación de lugares con una fuerte carga simbólica y vivencial, con el desplazamiento de personas para la rehabilitación de objetos. En efecto, esta economía de la restauración tiende a separar de los lugares a quienes los frecuentan, "en este caso particular, no resulta sorprendente que las administraciones técnicas se interesen tanto en los edificios y tan poco en los habitantes ... la rehabilitación participa en efecto en la "medicalización” del poder (De Certau y Giard, 2010, p. 142).

\section{Memoria urbana, relatos y simbolización de la ciudad}

La idea de un encuentro en la ciudad con sus respectivos relatos y configuraciones en la memoria supone en el recorrido urbano una manera de apropiarse de la historia de las calles, edificios, el recuerdo de lugares, recuerdos personales, tales como por ejemplo las experiencias en los diferentes metros de Europa o la rememoración de acontecimientos como la caída del muro de Berlín, la liberación de París, entre otros. Es necesario aclarar que esta postura no rechaza la dimensión material que resulta indispensable para la comprensión de la ciudad memoria.

Así, la ciudad memoria requiere ser encontrada por medio de la simbolización de sí misma, su la dimensión imaginaria no puede escapar a las posibilidades de socialización que en este lugar se desarrollan; por tal razón una figura para simbolizar la ciudad puede ser la novela, en ella además de las dimensiones materiales se pueden rastrear imágenes de ciudad; sin lo imaginario, ya no habrá ciudad y viceversa (Augé, 2008).
De acuerdo a lo anterior, la comprensión que se tenga del espacio urbano, depende en gran medida, de cómo se disciernan las relaciones entre las diversas instancias sociales y la lógica del lugar; si bien la vivienda posee variadas cualidades, como expresión estética, como objeto del pasado o centro de la política, estas, en su gran mayoría, llevan a preguntarse por la manera cómo las sociedades adquieren ciertas relaciones con el espacio. De esta forma, los estudios que provienen desde la arquitectura, afirman desde múltiples perspectivas, el valor que representa para un lugar las construcciones realizadas en el espacio publico que pueden ser entendidos, de acuerdo a diferentes valoraciones como patrimonio urbano (Pérgolis,1994; Viviescas,1994; Moure, 1994; Lom bardi,1994; Saldarriaga, 2002).

Por otro lado, si se toma a la ciudad en su conjunto como un patrimonio, se logra observar una superposición de tiempos, bajo la oposición entre lo nuevo y lo viejo en los espacios citadinos. Como consecuencia de esta oposición, se generan nuevas valoraciones de los diversos espacios urbanos lo que impide que la ciudad, $-y$ con ello su estructura patrimonial- pueda ser pensada como una totalidad y deba ser afrontada desde la lógica de los fragmentos (Llano 2010 citando a Cortés, 1994). Esta fragmentación de la ciudad implica además un ejercicio de poder para lograr la organización espacial (Zambrano, 1990; Aprille Gniset, 1990). A esta reacomodación espacial, producto de las relaciones de fuerza interpuestas por diferentes instancias se suma la regulación de los usos espaciales de los lugares públicos por parte del Estado para buscar una coherencia entre las prácticas

5 "La legitimación de ciertos objetos materiales y simbólicos, lugares, prácticas como patrimonio, en cada contexto histórico especifico, requiere de una codificación, interpretación e institucionalización, que conllevan en sí mismas una referencia al poder ... todo patrimonio se constituye a través de una puesta en escena que incluye operaciones de selección, combinación, monumentalización, miniaturalización y olvido, y lo hace al servicio de un proyecto político, en el que se ordena y se da un sentido y una propiedad a ciertos bienes, para establecerlos como 'verdaderos'" (Bustos, 2010). 
de los sujetos y los sitios públicos alrededor de un proyecto oficial que reafirma las posiciones sociales que se imponen en las dinámicas del poder (Llano, 1994, pp. 231-237).

Esta producción simbólica de la ciudad, relacionada con practicas y la regulación del espacio publico supone además unas configuraciones culturales dadas por el ritual, la ciudad convierte sus lugares en espacios propicios para ciertos rituales transformándose en una de las mayores estrategias que poseen los grupos dominantes para insertar su producción simbólica, por tanto, el ritual espacializado se convierte en lugar proclive para la imposición de toda una serie de significados y de representaciones sociales, las cuales son precisamente las que se transmiten a través del patrimonio urbano (Calvo,1998).

Finalmente para que el patrimonio urbano, en su condición de mecanismo simbólico, pueda operar como producto cultural, se hace necesaria la inversión simbólica, del campo de la arquitectura, sumada a los agenciamientos de diferentes grupos en el espacio social que a través de luchas buscan objetivar unos valores sociales en el espacio físico por medio de la arbitrariedad cultural ${ }^{6}$. En efecto, el patrimonio Urbano como una de las estrategias

6 La noción de arbitrariedad cultural procede de la teoría de la reproducción de los sociólogos Pierre Bourdieu y Jean Claude Passeron, quienes entre los años sesenta y setentas propusieron que la reproducción de las relaciones sociales y la configuración de las clases sociales son el resultado de una acción pedagógica con los efectos de una violencia simbólica encarnada en la escuela como institución social. Se retoma esta noción en la medida en que este concepto permite pensar en las condiciones sociales de producción y reproducción del orden social bogotano, que no ha procedido como reproducción mecánica, sino como resultado de unas fuerzas sociales en constante lucha por la imposición de un principio de visión y de división del mundo. En este sentido asumo la postura de Bustos (2012) quien propone pensar el patrimonio cultural de Bogotá, incluido el patrimonio urbano, no como algo neutral, trascendente y esencial, relativo a un colectivo social, sino como sistema arbitrario de valor y de significado, que estructura una serie de posesiones materiales o simbólicas. utilizadas para desactivar las contradicciones sociales logra naturalizar, unos estilos de vida dominantes en el espacio social a través de legitimación y las diferentes representaciones que se imponen (Llano, 2010).

\section{Metodología}

Los aspectos metodológicos utilizados en esta investigación se inclinan a indagar los elementos relacionales de la apropiación del espacio urbano y su conexión con los aspectos sociales y culturales alrededor del concepto de patrimonio urbano explicado en la sesión anterior. Se toman en cuenta los aportes conceptuales y metodológicos de Bourdieu, como las nociones de espacio social, campo, habitus y arbitrariedad cultural, capaces de plantear un acercamiento más próximo entre teoría y práctica para rastrear las relaciones que los bogotanos que habitaron la ciudad entre los años 1850 a 1880, tenían con el espacio urbano y las dinámicas sociales y culturales que suponía esta relación. Para indagar empíricamente las relaciones del espacio social se rastreo inicialmente los comportamientos y la vida cotidiana de los diferentes grupos sociales bogotanos de la época estudiada a través de fuentes primarios como los relatos de viajero que evidenciaron las creencias sobre la vida urbana.

A partir de los testimonios que dejaron los viajeros extranjeros de la época se realiza una interpretación de tercer orden, para lograr desentrañar las estructuras de significación de los estilos de vida, entendidos como la realización de los habitus provocados por el espacio social. El análisis de los documentos, se trata de relatos de viajeros o fuentes secundarias son interpretados teniendo en cuanta que el documento es ante todo una producción, en la que se ponen a circular discursos sociales interpretados y analizados por el autor del documento. En tal sentido, se hizo relevante contextualizar los documentos producidos por la cultura, para no tomarlos como calcos de la realidad; es por esto que se hizo necesaria su crítica como monumento para evidenciar 
las condiciones históricas de su producción (Le Goff, 1991, p. 239).

De este modo, la cultura se tomó como un documento público dispuesto a ser interpretado, en palabras de Geertz, la interpretación de la cultura es definida como un acto complejo, de interpretación densa, es como tratar de leer un manuscrito extranjero, borroso, plagado de elipsis, de incoherencias de sospechosas enmiendas y de comentarios tendenciosos y además escrito no en las grafías convencionales de representación sonora, sino en ejemplos volátiles de conducta modelada (Geertz, 1996, p. 24). De esta manera, la cultura es planteada como un contexto donde, los fenómenos pueden describirse de manera inteligible. Esta noción de cultura planteada como documento y contexto se hace relevante para el análisis y la interpretación de las condiciones de producción de estas identidades. En efecto, las condiciones de producción de las identidades que se construyen por medio de confrontaciones sociales, son fuente vital para la interpretación de los discursos sociales y el desarrollo del análisis cultural que se desenvuelve según una secuencia discontinua pero coherente de despliegues cada vez más audaces (Geertz, óp. cit., p. 36).

Por último, un análisis del patrimonio urbano como inversión simbólica quedaría incompleto si no se describen las fuerzas que lo agencian. En efecto, estas relaciones de fuerza se pueden evidenciar en las relaciones espaciales que traen unas las objetivaciones del espacio social, esto es, que el espacio físico trae consigo unas propiedades que sólo son explicables si se ponen en relación con otros espacios físicos. Las cualidades que le son inherentes y la escala de valor con la que son percibidos son otorgadas por el espacio social para

$7 \quad$ El espacio urbano debe sus condiciones de existencia a las relaciones que se desatan entre los diferentes agentes del espacio social, encaminadas a imponer en el espacio físico la distribución de unas formas objetivadas de capitales socialmente existentes en el espacio social. Estas formas objetivadas encuentran su expresión en múltiples manifestaciones, en un recorrido que involucra desde el conjunto generar distinciones sociales (Bourdieu, 1999, pp. $119-124)^{7}$.

\section{Resultados}

\section{Ciudad estática y sociedad jerárquica (1850-1880)}

En el siglo XIX el espacio urbano bogotano se caracterizó por su lento crecimiento y por mantener una relación jerárquica en el espacio social. La vieja ciudad santafereña durante gran parte del siglo XIX mantuvo sus límites casi intactos, con san Diego al norte, san Cristóbal al sur y san Victorino al occidente, mientras permanecía replegada en el pie de los cerros orientales. En este sentido, la ciudad, seguía conservando su estructura inicial heredada de la colonia, donde su área no sobrepaso los limites de la calle 26 hasta la calle 1 y desde la actual carrera 2 hasta la carrera 14. Desde este escenario geográfico Bogotá presentó un progreso lento desde el punto de vista del desarrollo urbanístico, sus límites seguían conservando la misma topografía colonial, donde la vida social se desarrollaba alrededor de la catedral y la plaza central ${ }^{8}$.

de adecuaciones arquitectónicas y urbanísticas que en determinadas circunstancias históricas modelizan la diversidad de entornos urbanos y la ciudad en su generalidad, hasta las disposiciones que definen las formas de participación de los agentes en la urbe a propósito de este conjunto de adecuaciones que no son, por todo lo anterior, sino mecanismos objetivantes de la globalidad de capitales que están en juego en el espacio social. Por esto a la inminencia de los efectos económicos en la constitución del espacio urbano, se suman los efectos de unas dimensiones políticas, culturales y estéticas, que operando dentro de estos mecanismos, bajo el auspicio de los propios efectos económicos, afianzan ecológicamente a la ciudad en ajustes a las expectativas de los estilos de vida de los diferentes sectores y clases sociales.

8 El dato proporcionado por Peralta resulta significativo para este caso. Hacia 1820 el área de la ciudad era 203 hectáreas dividido por 21. 394 habitantes darían un promedio de $95 \mathrm{mts}$ por habitante y a finales de siglo, suponiendo que el área no se ensanchara, dividiendo por 100.000 habitantes daría un promedio de $20.3 \mathrm{mts}$. por habitante (Mejía, 1985, citado por Peralta, 1995, pp. 32-33). Esto supone que la ciudad 
A lo largo de todo el siglo XIX, esta área urbana casi no creció a pesar que la población se quintuplico, es así como se realizó una utilización más intensiva del espacio urbano gracias a un cambio de nuevas casas construidas y, sobretodo, a la subdivisión de las ya existentes (Fundación misión Bogotá, 1988) $)^{9}$. Esto produjo una contención de las innovaciones en la ciudad, ya se tratara de ampliación de servicios públicos, de la proyección de nuevas construcciones en la ciudad o del incremento de espacios públicos para la ciudad ${ }^{10}$.

Con escases de espacios urbanos era posible reafirmar una sociedad jerarquizada, blanco de las criticas por parte de sectores liberales, cuyo representante mas acérrimo de la herencia colonial fue el liberal Samper quien publicó un manuscrito que tituló la miseria en Bogotá para denotar la indigencia, indignación y vergüenza que promocionaba el modelo económico colonial y la ausencia de desarrollo urbano (Samper, 1898/1998).

De tal modo, el modelo espacial colonial se mantenía, permitiendo el hacinamiento y la proximidad física entre los habitantes de la ciudad. Era recurrente observar como producto de la poca expansión física de la ciudad una cercanía de las clases sociales en el espacio urbano, lo que condujo a las clases altas a formular estrategias de diferenciación social. En efecto, la proximidad espacial,

no se desarrollo urbanísticamente sino que su población se hacino.

9 En realidad era tan frecuente la proximidad entre las clases sociales que se dio el caso en que las casas de dos pisos eran subdivididas, conviviendo en el mismo inmueble gentes aristocráticas y acaudaladas en el segundo piso, con moradores paupérrimos en el primero (Martínez citado por Peralta, 1995, p. 33).

10 Durante todo el siglo XIX el espacio urbano bogotano, careció de mecanismos suficientes de provisión de agua que lograran un completo abastecimiento para los ciudadanos de la urbe, su construcción generalmente era lenta debido en gran medida a la falta de recursos necesarios para tal empresa. ... la petición inicial de este acueducto se hizo en 1680, en 1792 se continúo la obra, y en 1801 se obtuvieron los dineros que permitirían concluirla en 1803 (Rodríguez, 2003, p. 121).

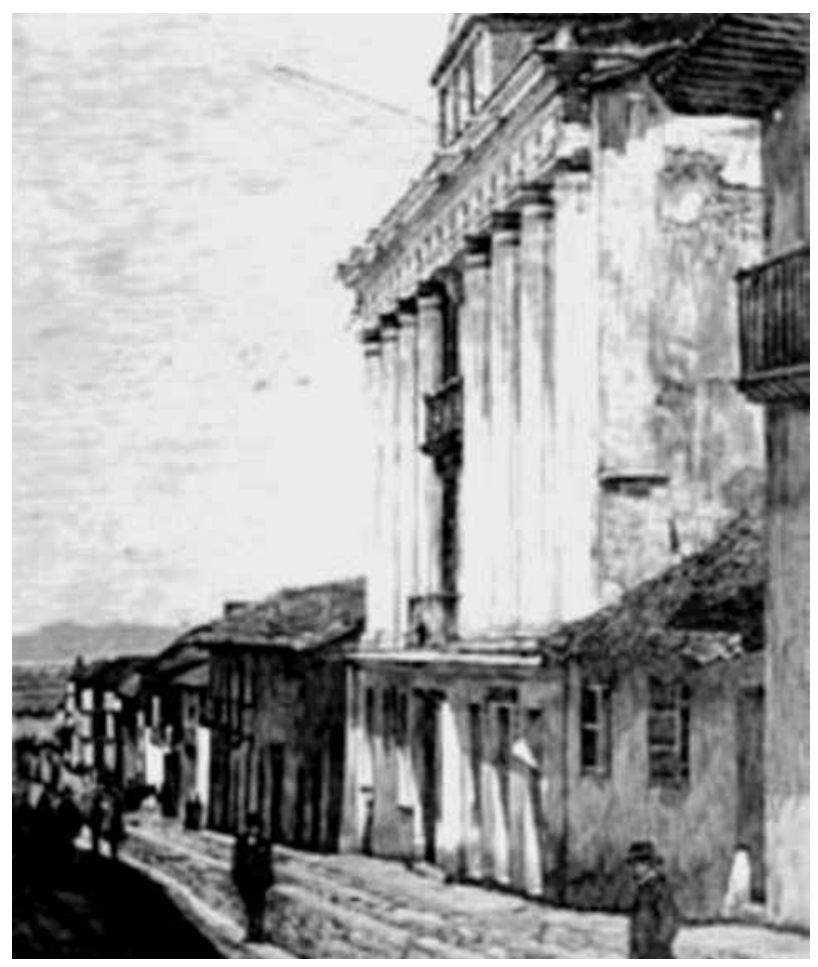

la pobreza casi compartida del aspecto exterior de calles y fachadas y la coexistencia de las jerarquías en la vía y los lugares colectivos como en algunas casas, no permitía reafirmar en la inminencia del espacio urbano, como espacio físicamente sustentable, las distancias abismales que existían al interior de la ciudad y que, por el contrario, sólo podían ser reafirmadas sobre el propio principio de proximidad (Serna, 2001).

Ante la carencia de espacios públicos, la estrategia utilizada por la élite bogotana consistió en tratar de dotar la ciudad de espacios donde simultáneamente podían servir como sitio de encuentro, a la vez que se convirtieron en los territorios para incorporar la nueva taxonomía social; una muestra de lo anterior, se refleja en la necesidad de abrir nuevos teatros, espacios propicios para dar a conocer los nuevos estilos de vida, que buscaban imponerse en la ciudad. Al respecto, Pedro María Ibáñez, comenta como el inicio de las obras del teatro municipal a cargo del arquitecto Mariano Santamaría o la expropiación del teatro Maldonado -posteriormente Teatro Nacional-, respondían a las "crecientes exigencias sociales de la capital", que 
bien podemos señalar como las intenciones de la nueva élite que intenta imponer su visión de ciudad sobre los demás grupos sociales (Ibáñez, 1989).

Un ejemplo espacial de esta proximidad y a la vez un ejemplo de diferenciación social en lugares cercanos lo constituía el altozano que se consagraba como el lugar por excelencia, de la gente distinguida y culta de la ciudad como lo manifiesta Cané:

Pero, me diréis, ¿los bogotanos no pasean, no tienen un punto de reunión, un club, una calle predilecta, algo como los boulevares, nuestra calle Florida, el Ring de Viena, el Unter den Linden de Berlín, el Corso de Roma, el Broadway de Nueva York ó el ParkCorner de Londres? Sí, pero todo en uno: tienen el altozano. Altozano es una palabra bogotana para designar simplemente el atrio de La Catedral, que ocupa todo un lado de la Plaza de Bolívar, colocado sobre cinco ó seis gradas y de un ancho de diez á quince metros. Allí, por la mañana, tomando el sol, cuyo ardor mitiga la fresca atmósfera de la altura, por la tarde, de las cinco á las siete, después de comer (el bogotano come á las cuatro), todo cuanto la ciudad tiene de notable, en política, en letras ó en posición, se reúne diariamente (Cané, 1891).

Fueron esporádicas las residencias que se construyeron en la ciudad dentro de los nuevos parámetros, ya que la distinción social seguía permaneciendo en el interior de las viviendas (Rawitscher, 2000) ${ }^{11}$.

11 Los criterios de distinción, no recaían en las fachadas de estas casas sino al interior de ella, donde se constituía en un centro social por excelencia, a través de las fiestas y celebraciones privadas que eran las actividades para introducir los nuevos sentidos legítimos de la existencia, cumpliendo de esta manera la labor de dar a conocer las nuevas divisiones del mundo social. En este sentido, la dinámica que se establecía en torno al interior de las casas de la elite bogotana, mostraron una mayor incidencia de los bienes de consumo que vinculaban a estas posiciones con el universo de lo público, transformando de esta forma, los parámetros de lo público y lo privado.

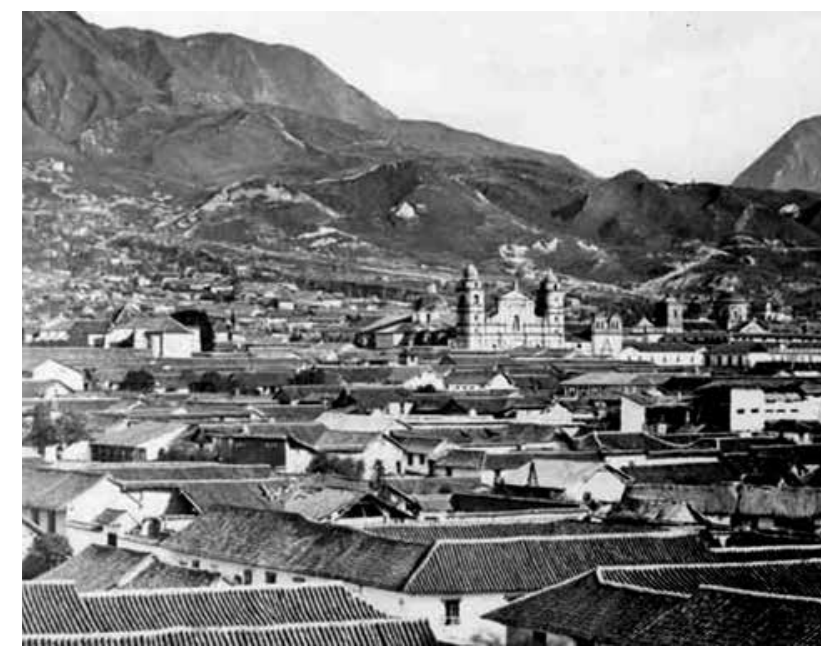

En este sentido, como la vida social se desarrollaba al interior de las casas, específicamente en la sala, los gustos legítimos de la existencia ponían de manifiesto unas condiciones para lograr la distinción. "El lujo en la sala, aunque expresión de una actitud esnobista, también estaba relacionado con un aumento en el bienestar económico de un sector importante de la capital. El caudal promedio de los inventarios entre 1820 y 1846 era de $\$ 40.047 .46$. Esta cifra resulto casi duplicada entre 18541882 [\$ 75. 292.67]. El valor de la sala, por su parte paso de un promedio de $\$ 331.93$ en el primer periodo mencionado, a $\$ 1.076 .5$ en el segundo periodo, mostrando un aumento de 3.24 veces. En este sentido la sala debía tener: alfombra y papel colgado; los muebles debían estar acorde en diseño, tamaño, tipo de madera y forros, es decir, en estilo; debían estar a la moda y por lo mismo debían ser importados; no debían disfrazar la madera barnizándola; la sala no debía exhibir muebles en mal estado, asientos de guadamacil, ni enseres que -como el ropero y la cómoda- no correspondieran al lugar; desde la sala no debía verse el interior de la alcoba; el salón debía exhibir cielo raso del que debía colgar una sola lámpara (y no bambas de vidrio)" (Lara. 1997, p. 102]

Es importante resaltar, que estas tensiones entre unos sectores conservadores del orden social invariante y unos críticos que buscaban con afán el crecimiento y transformación de la ciudad, 
se desarrollaban en un ambiente económico que posibilitaba una tenue transformación en el escenario bogotano y en las actividades publicas. Paralelamente a los beneficios que obtenía la economía nacional como producto del llamado ciclo de las exportaciones (añil, quina, caucho algodón y tabaco) empezaron a circular de manera gradual por dicho escenario una serie de innovaciones que, sumadas a cierta ampliación del universo de bienes de consumo, señalaron unos tímidos esbozos de conversión de los patrones de vida publica en la ciudad y, con ellos, de los espacios en que se desenvolvían, unos y otros de fuerte raigambre colonial (Zambrano, 1994, Rawitscher, 2000).

De la misma forma, se realizaron cambios en las actividades de diversión y ocio, con el fin de ocupar un nuevo lugar diferenciante con las actividades de otros grupos sociales. Caso paradigmático lo representan actividades como las peleas de gallos que eran símbolos de las actividades propias de la sociedad colonial; un ejemplo de ello nos lo muestra Gosselman oficial de la marina sueca, quien a su paso por Bogotá, dejo las siguientes impresiones: "Excepto este [las peleas de gallos], los habitantes de la ciudad no asistían a otra representación, ya que a pesar de que allí haya un teatro grande y bien construido, se representan muy pocas obras en el" $(1827,158$ citado en Fischer, op. cit).

Percepción similar generaban las corridas de toros, donde en un principio asistían gentes de todas las clases sociales. En efecto, los estudiantes toreaban con el capote; el pueblo con la ruana, y los cachacos, con el pañuelo; en su entusiasmo por divertirse, las últimas llegaban hasta quitarse la levita, para torear con ella, con lo cual quedaban de cuerpo de camisa y sombrero de copa alta. La aporreada de esos petimetres causaba gran hilaridad y regocijo, y si el toro derribaba a un hombre del pueblo, se oía en voz unísona: ¡Lo mató! (Cordovez Moure, 1957/2004 p. 109].

Sin embargo, a partir de las transformaciones antes mencionadas, comenzaron a observarse de mal gusto, ya que, este no tenía las "propiedades estéticas" que le imprimía la élite en España. Hasta el año 1890, en que vino a esta ciudad la modesta compañía de toreros americanos compuesta por el director Manuel González (clown), torero; de los banderilleros Rafael Parra (cara de piedra); de los capeadores, Julián González (regaterin) y julio Ramírez (fortuna), no tenían ni idea los santafereños de lo que era una corrida de toros al estilo español, en las que todos son reglas fijas y posturas académicas, con cierta gravedad y compostura aún en las suertes más arriesgadas (Cordovez Moure, op. cit., 84). En este sentido, las prácticas populares concernientes a las corridas de toros, fueron consideras como prácticas bárbaras, que daban cuenta del salvajismo de las clases bajas de la ciudad; aun así, para comienzos del siglo veinte se conservaba como una forma de pasar el tiempo libre.

Finalmente, la crítica a la precariedad del espacio urbano por parte de nuevos actores sociales, la aparición de estamentos especializados en su recuperación y preservación así como en la construcción y urbanización cualificada, los atentados a las construcciones en medio de las reyertas políticas y la emergencia de nuevos espacios a propósito de importantes conmemoraciones cívico-patrióticas, ubican toda una preocupación novedosa, sobre el espacio urbano y advierten algunas de las escenas donde se desplegará la lucha por la imposición de unos sentidos legítimos de la existencia ${ }^{12}$.

12 Estos efectos simbólicos en la ciudad, tomaban la forma de prácticas altamente visibilizadas en el entorno urbano, en la medida que lograban derivar comportamientos de clase para constituir identidad e imponer unas visiones de las conductas deseables en la ciudad. Estas practicas de las buenas maneras, del buen hablar de los modales y la etiqueta, estarán presentes en los estilos de vida de la ciudad entorno a un proyecto cultural, bajo la asimilación de modelos extranjeros, para disimular la manera como se distribuían los bienes de distinción en el universo social bogotano en un espacio social fuertemente jerarquizado que imposibilitaba el ascenso social. 


\section{Conclusiones}

Después de 1850 era evidente el panorama en cuanto al llamado urgente de los habitantes de la ciudad para que agentes de su misma clase adoptasen el paradigma del "buen vivir europeo". Consecuencia de la obtención de las utilidades económicas se proyectaron cambios de manera contundente en la vida cotidiana de grupos sociales altos de Bogotá, muy pronto se observaron formas de diferenciación basadas por la capacidad de lujo y ostentación, que básicamente rompía con el modelo de austeridad propio de las estructuras coloniales; la ostentación y la suntuosidad son dos principios determinantes del nuevo estilo de vida de las élites Bogotanas (Fischer, 1999. Mejía, 1888], que comenzaba su dificultoso camino para consolidar un estilo Burgués con un sentido legitimo ${ }^{13}$.

Estos dividendos, no se expresaron de manera equitativa en las clases sociales medias y bajas. En contraposición al estilo de vida de las élites capitalinas, las condiciones de existencia para los grupos sociales medios y bajos se podrían definir esencialmente por su precariedad. Un informe de esta situación, lo ofreció las condiciones de hacinamiento en las que vivían las clases medias y bajas, lo que además las hacían proclives a las múltiples epidemias que de continuo se presentaban en la ciudad. Si observamos la densidad por manzana "para el periodo 1881-1906 la densidad absoluta bajó de 486 a 335 habitantes por manzana, y que se abrieron nuevos espacios en la ciudad, los cambios y el crecimiento físico significaron muy poco para los sectores sociales más bajos" (Mejía, op. cit. 33) En consecuencia, muchos habitantes vivian en una ciudad pequeña, que no se extendió sino que se ensancho hacinando a la población en las grandes

13 Mejía Pavony ubica para este mismo periodo la llegada de un estilo aburguesado, sin intentar negar esta afirmación- como veremos más adelante-, habría que diferenciar el momento de su aparición, con el momento de su legitimación. casas que se subdividían y hacían las veces de los inquilinatos actuales. En 1891 había un promedio de 10 habitantes por casa [Peralta: 1995:33].

Estos lugares donde se ubicaban las clases sociales de menor proyección eran conocidos para la época con el apelativo de tiendas. Ciertamente, estos lugares confirman las pésimas condiciones que les ofrecía la ciudad para resolver su existencia: “...todavía una buena parte de la gente pobre vive amontonada en tiendas que principalmente son los bajos delanteros de las casas altas, focos de inmundicias una vez que se las dejó subsistir después de suprimir los arroyos de las calles convertidos en sui-generis alcantarillas (Vergara y Velasco, 1901, p. 666, citado en Mejia, op. cit., 32).

El caso de las clases bajas todavía es más extremo. Este grupo social no tuvo acceso a la posesión de capitales y encontraba como única forma de existencia la mendicidad, o el reclutamiento de manera obligatoria para las guerras civiles. En efecto, esta era la clase de los marginados, ausente de participación alguna en las decisiones políticas e imposibilitada para diversificar los roles consuetudinarios que imponían los linajes decimonónicos con base en la vieja factura colonial, solo tuvo como alternativa el reclutamiento en las filas de los ejércitos [habitualmente de manera forzosa] clase de los condenados naturales en la percepción de las otras clases, era vista por éstas, de manera contradictoria, como el refugio de las virtudes naturales o como el bastión de las virtudes patrióticas, unas y otras traumatizadas por las formas históricas de dominación. Las condiciones de existencia de este grupo social, eran paupérrimas, vivían por lo general en casas de techos de paja y chozas, por supuesto, constituían el grupo al que más se le aplicaba la diferenciación social, conminándolos a vivir a los alrededores de la ciudad, especialmente en la parte oriental de la ciudad.

Finalmente, bajo esta condición, donde lo público y lo privado se presentaban en equilibrio, se puede afirmar que en la ciudad del siglo XIX se desataba una intensa vida pública marcada coti- 


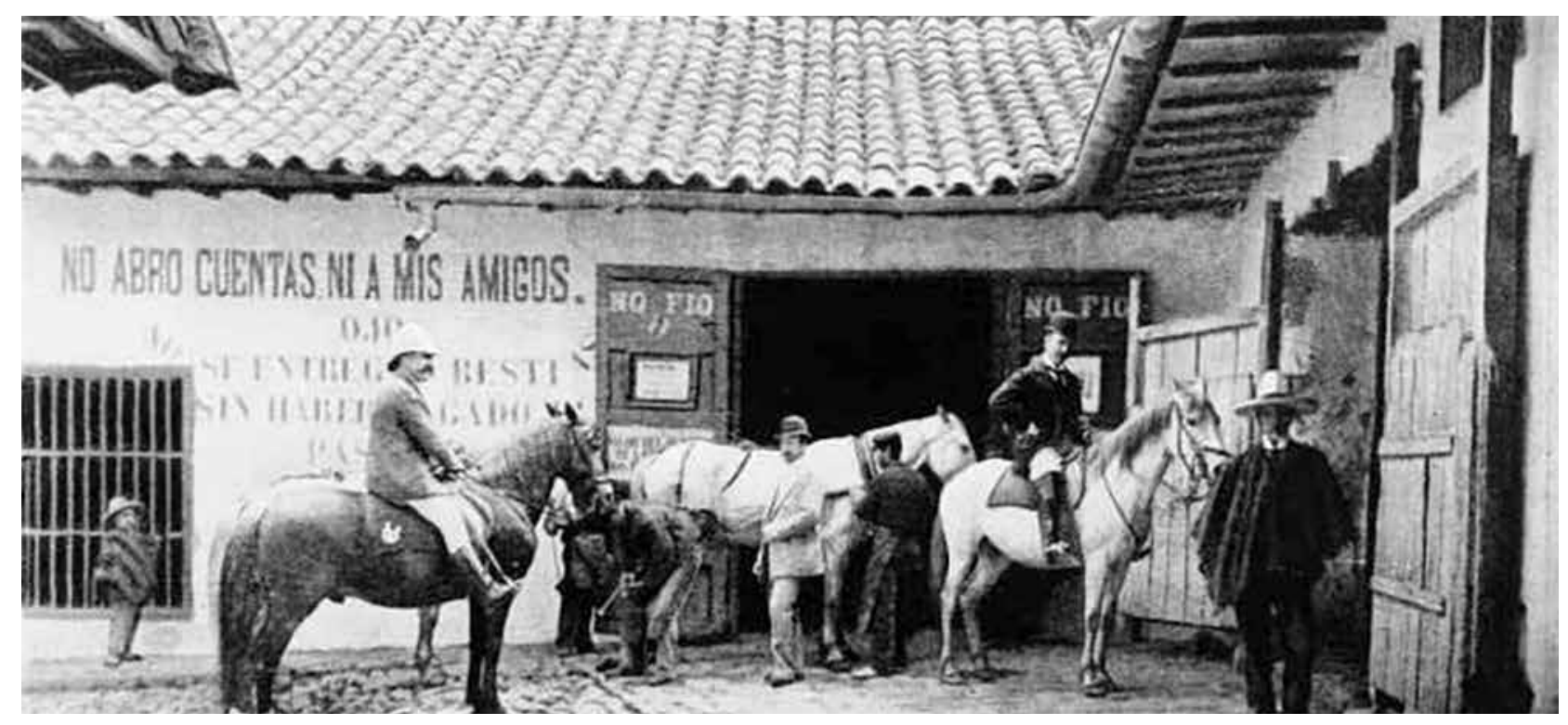

dianamente por unos sentidos de preservación de la diferencia visibles en la urgencia por los vestuarios, por los modales y las maneras por el protocolo, que tanto impactaron a los viajeros y huéspedes que se alojaron en la capital, todas ellas representadas en figuras características, como las del cachaco y el pepito. El afán por los sentidos de la diferencia, por el ejercicio permanente de la distinción, fue tanto el producto de la proximidad de las jerarquías como del mismo hecho de que ésta favorecía desplazamientos raudos entre las posiciones de las clases sociales dominantes, situación auspiciada por el carácter reducido y no siempre bien fundado de la nobleza criolla, a la cual se vino a sumar la capacidad de ascenso que adquirieron algunos sectores a través de vetustas herencias, de los beneficios de alguna empresa rentable a propósito de las accidentales bonanzas del siglo así como por el acceso a determinados bienes, producto habitualmente de fugaces estadías en Europa.

\section{Referencias}

$\diamond$ Achugar, H. (1999). "El lugar de la memoria", en Cultura y globalización, comp. Barbero, Jesús Martín. Universidad Nacional de Colombia. $\diamond$ Auge, M. (1993). Los no lugares. Espacios del anonimato para una antropología de la sobre modernidad. Barcelona: Gedisa editorial.

$\diamond$ Bonal, X. (1998). Sociología de la educación. Una aproximación critica a las corrientes contemporáneas. Barcelona: Ediciones Paidós.

$\diamond$ Bourdieu, P. (1990). "Espacio social y génesis de las clases”, en: Sociología y cultura. México: Grijalbo.

$\diamond$ - (1991). El Sentido práctico. Madrid: Editorial Taurus.

$\diamond \quad$ - (1997). Razones prácticas, sobre la teoría de la acción. Barcelona: Anagrama.

$\diamond \quad$ - (1999). Efectos de lugar en la miseria del mundo. México: Fondo de cultura económica.

$\diamond \quad-$ (1999). La distinción. Criterios y bases sociales del gusto. Madrid: Taurus.

$\diamond \quad$ - y Wacquant, L. J. (1995). Respuestas por una antropología reflexiva. México: Grijalbo.

$\diamond$ Bustos, M. (2010, enero-junio). "El patrimonio y la lucha por los sentidos en el distrito capital”, en: Revista Calle 14, vol. 4, n. ${ }^{4}$.

$\diamond \quad$ Calvo, O. I. (1998). El cementerio central: Bogotá, la vida urbana y la muerte. Bogotá: Observatorio de Cultura Urbana.

$\diamond$ Castro, B. (1988). Historia de Bogotá. Fundación Misión Colombia. Bogotá: Villegas Editores.

$\diamond$ Deas, M. (1993). Del poder y la gramática y otros ensayos sobre historia política y literatura colombiana; 
miguel Antonio Caro y sus amigos: gramática y poder en Colombia. Bogotá: Tercer Mundo Editores.

$\diamond \quad$ Del Castillo, J. C. (2003). Bogotá: el tránsito a la ciudad moderna 1920-1950. Colombia: Universidad Nacional de Colombia.

$\diamond \quad$ Fisher, T. (1999). "La gente decente en Bogotá. Estilo de vida y distinción en el siglo XIX visto por viajeros extranjeros", en: Revista Colombiana de Antropología, vols. 35-39.

$\diamond$ Iriarte, A. (1988). Breve historia de Bogotá. Bogotá: Editorial Oveja Negra.

$\diamond$ Le Goff, J. (1991). “Documento / monumento", en: Orden de la memoria. Barcelona: Ediciones Paidós, pp. 227-239.

$\diamond$ Llano, M. C. (1994). "Plaza de Bolívar: la manzana de la discordia", Pobladores urbanos, comp.: Julián Arturo. Colombia: TM editores - Icanh, pp. 211-237.

$\diamond \quad$ Maldonado, J. y Alvarado, J. (2003). “Formas públicas de la arqueología y discursos escolares: poder, memoria y pedagogía a través de las representaciones del pasado", Arqueología al desnudo: reflexiones sobre la práctica disciplinar. Gnecco Cristóbal y Piazzine Emilio (comps.) Popayán: Universidad del Cauca.

$\diamond \quad$ Martínez, F. (2000). “¿Cómo representar a Colombia? De las exposiciones Universales a la Exposición del Centenario 1851- 1910", Museo, memoria y nación. Misión de los museos nacionales para los ciudadanos del futuro. Gonzalo Sánchez Gómez, María Emma Wills Obregón (comps).

$\diamond$ Mejía, G. R. (1988). "Bogotá: condiciones de vida y dominación a finales del siglo diecinueve”, en: Boletín de Historia, vol. 5. $\diamond$ Melo, J. O. (1991). "La república conservadora”, en: Colombia hoy: perspectivas hacia el siglo XXI. Bogotá: Siglo XXI editores.

$\diamond$ Rabinow, P. (1991). "Las representaciones son hechos sociales: modernidad y postmodernidad en la antropología", en: Retóricas de la antropología. California: Ediciones Júcar, pp. 318-356.

$\diamond$ Rodríguez, L. E. y Núñez, C. S. (2003). Empresas públicas de transporte en Bogotá. Siglo XX. Bogotá: Alcaldía Mayor de Bogotá.

$\diamond$ Sánchez, J. D. (2003). Temo profanar tu nombre. Construcción del mito político del héroe. Bogotá: Universidad Distrital Francisco José de Caldas.

$\diamond$ Serna, A. (2001). Próceres, textos y monumentos: culturas urbanas, discursos escolares y formas de la historia: Bogotá (1938- 1991). Bogotá: Universidad del Bosque.

$\diamond$ Serna, A. (2004). "Identidad ciudadana y vida pública: La cuestión de la identidad", en: Revista Científica, No. 6, Universidad Distrital Francisco José de Caldas.

$\diamond$ Serrano, R. (1981). Aquella ciudad. Crónica mínima de Bogotá. Bogotá: Ediciones Tercer Mundo.

$\diamond \quad$ Viviescas, F. (1994). "El problema cultural de la ciudad colombiana y la arquitectura”, en La ciudad como bien cultural. Memorias del seminario. Santafé de Bogotá: Colcultura.

$\diamond$ Yory, C. (1998). "La topofilia: una estrategia innovadora de desarrollo sustentable para las grandes metrópolis latinoamericanas en el contexto de la globalización", en Anales de Geografía. Madrid: Universidad Complutense. 